\title{
Respiratory illness healthcare-seeking behavior assessment in the Lao People's Democratic Republic (Laos)
}

Mayfong Mayxay ${ }^{1,2,3^{*}}$, Visanou Hansana ${ }^{1}$, Bouachanh Sengphilom', Latsamy Oulay ${ }^{1}$, Vatsana Thammavongsa ${ }^{1}$, Vatsana Somphet ${ }^{1}$, Chansathit Taykeophithoune', Soudavanh Nathavong', Johnly Phanthady', Kongmany Chareunvong ${ }^{1}$, Phetsavanh Chanthavilay ${ }^{1}$ and Vanphanom Sychareun ${ }^{1}$

\begin{abstract}
Background: Respiratory illness (RI) remains a public health problem in Laos, but little is known about the overall burden and people's healthcare-seeking behavior for Rl. Understanding the burden of Rl and community patterns of healthcare-seeking behavior would provide better guidance for Lao public health program and policy planners to improve RI public health practice, surveillance systems, and prevention strategies.

Methods: A quantitative and qualitative survey was conducted in 14 randomly selected villages of two purposively selected peri-urban and two rural provinces in Laos. A pre-designed and pre-tested questionnaire was used to collect information on RI in household members (defined as new fever with cough and/or sore-throat in the absence of other diagnoses during the preceding 30 days) from all heads of household in each village. Sixteen focus group discussions were conducted to obtain more information to support the quantitative survey.

Results: Among 1,751 households $(9,114$ people) studied, 3.5\% $(317 / 9,114)$ had experienced Rl (fever, cough, and/or sore-throat) in the 30 days before the survey [ $6.2 \%$ in rural and $2.4 \%$ in peri-urban areas $(p<0.001)]$. The percentage of $\mathrm{Rl}$ among persons aged $\geq 15$ years was $2.7 \%, 3.7 \%$ for those aged $5-14$ years, and $8.2 \%$ for children $<5$ years $(p<0.001)$. Of all sick persons, $71 \%$ sought treatment $[94 \%$ in peri-urban and $48 \%$ in rural areas $(p<0.001)]$ and $31.5 \%$ of them self-medicated $[55.5 \%$ in peri-urban and $29 \%$ in rural areas $(p<0.001)]$. Sick people in peri-urban areas preferred to chose private clinics and pharmacies as their first treatment option while in rural areas they frequently consulted with village health volunteers and visited health centres as their first choice. The qualitative study suggests that distance, costs of care, and service availability are the most important determinants of seeking healthcare.

Conclusions: The RI burden and healthcare-seeking behavior are different between rural and peri-urban areas of Laos and this is probably due to the differences in environmental and hygienic conditions, health service availability and socio-economic status between the two areas. Therefore strategies for healthcare service improvement may also need to differ between the two areas.
\end{abstract}

Keywords: Respiratory illness, Healthcare-seeking behaviour, Laos

\footnotetext{
* Correspondence: mayfong@tropmedres.ac

${ }^{1}$ Faculty of Postgraduate Studies, University of Health Sciences, Vientiane, Lao PDR

${ }^{2}$ Lao-Oxford-Mahosot Hospital-Wellcome Trust Research Unit (LOMWRU),

Microbiology Laboratory, Mahosot Hospital, Vientiane, Lao PDR

Full list of author information is available at the end of the article
} 


\section{Background}

Respiratory illness (RI) is a leading cause of death and disease burden worldwide [1,2] and about $95 \%$ of the deaths from RI occur in developing countries [3]. In the Lao PDR (Laos), RI is an important cause of morbidity and mortality, particularly among children, but very little is known about the overall burden of RI. The latest national health survey in 2000 demonstrated that $~ 1 \%$ of under-five children had had acute respiratory infection in the two weeks before the survey [4]. No RI surveillance system existed in Laos until recently, when a facility-based surveillance system was established that uses disease reports originating from hospitals and health centres. The capacity of this surveillance system to reflect the actual disease burden in the community may be limited.

Since healthcare seeking behaviors and healthcare utilization practices vary widely from one community to another, health utilization assessments can assist in identifying the extent to which facility-based data reflect the actual burden of disease in a community [5]. In addition, understanding community patterns of healthcare-seeking behavior (for example who in the community are the first points-of-care for villagers with RI) and reporting would improve public health practice in the community. This survey was conducted to provide better direction for Lao public health program and policy planners to improve public health practice, surveillance systems and prevention strategies, and to generate important information to help evaluate ongoing Lao Government health activities.

\section{Methods}

\section{Study duration and sites}

The study was conducted between 11 March and 12 April 2009 in peri-urban (Vientiane Capital and Vientiane Province) and rural (Sayabouli and Sekong Provinces) areas (Figure 1). These localities were chosen because they cover the range of peri-urban and rural areas, are sites for the development and piloting of village-based mechanisms to promote human and animal avian influenza surveillance and response, and had had previous avian influenza or influenza-like illness outbreaks. Vientiane Capital and Vientiane Province are located in central Laos, with 9 and 13 districts respectively, comprising both urban and periurban areas: one peri-urban district from each was studied. Sayabouli Province is located in northern Laos on the Lao-Thai border, with 10 districts which comprise largely rural areas, with some being very remote and poor. Sekong Province is located in southern Laos on the Vietnam border, with four districts comprising rural areas, and multiple ethnic minority groups [6]. One rural district from each of these provinces was selected for the study. During the study, the climate in Sekong and Xayabouli was relatively cool, while it was less cool in Vientiane Capital and Vientiane Province. The healthcare system in Laos

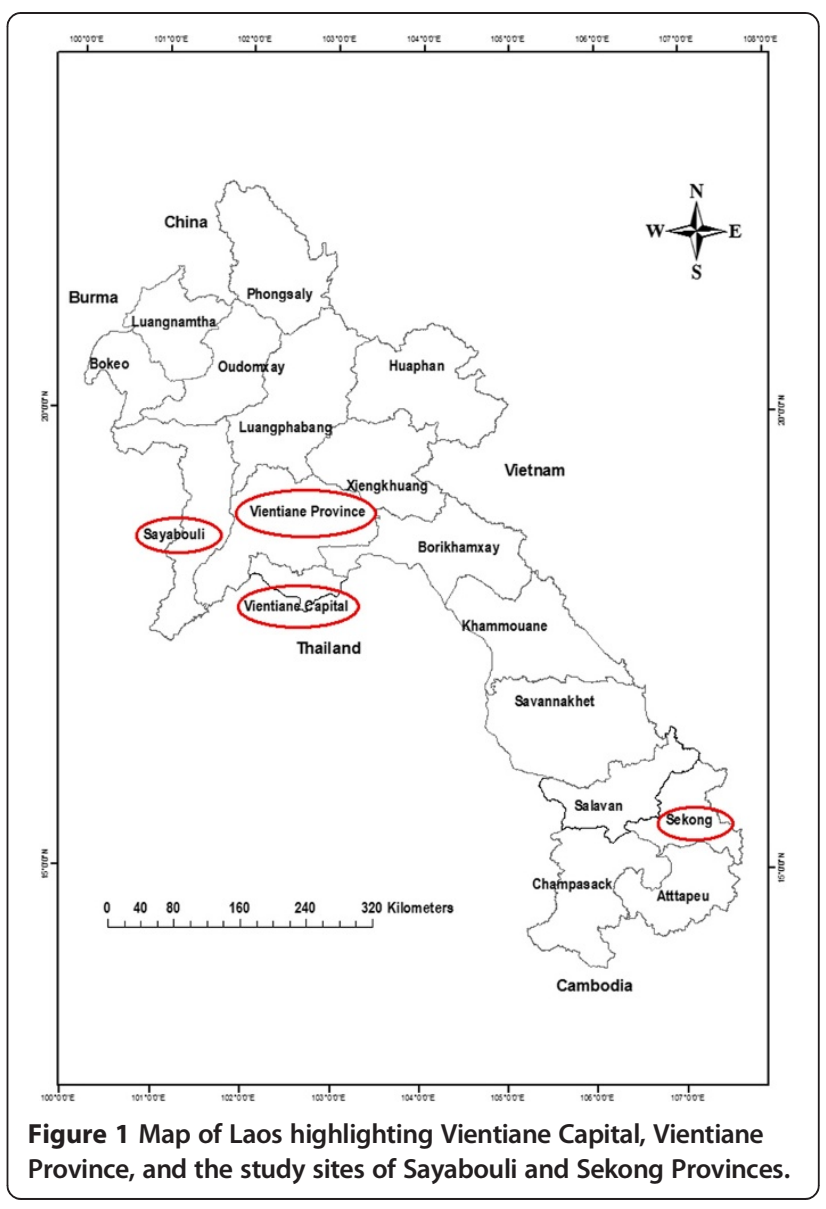

includes four levels: village, district, provincial and central. Village health volunteers (VHVs) (who are usually trained for 2 weeks on how to use basic oral medicines and provide primary healthcare services at their own homes) are the key health providers at the village level. In some villages, health centres are also available, but mostly nurses and medical assistants provide care. At district level, level A hospitals provide care that includes some surgery, while surgery is not undertaken at level B hospitals. The majority of healthcare providers at this level are medical assistants, with a small number of fully qualified doctors. Provincial hospitals provide a higher level of care including surgery and there are more doctors compared than at district level. Central hospitals are tertiary referral hospitals in Vientiane Capital where the majority of the providers are fully qualified doctors and specialists. At the time when the study was conducted, community health insurance schemes were not available at the study sites and these did not become available until the end of 2009. Therefore, people had to pay for their own healthcare throughout the study period.

\section{Definition of respiratory illness}

In order to enable comparisons between assessments, standardized definitions were used. The definition of RI 
was derived and modified from the WHO case definition for human infections with influenza A (H5N1) virus [2], namely: self-reported new fever with cough and/or a sore-throat in the absence of other diagnoses during the 30 days before the survey. This definition was agreed in consultation with experts from the CDC International Emerging Infections Program and the National Centre for Immunizations and Respiratory Diseases, Influenza Division.

\section{Sampling procedure and survey}

The provinces and districts were purposively sampled as mentioned above, while the villages were randomly selected from the village list of each district. Three villages were selected at random from each district and all households in the village were studied. All members of the households were eligible for the survey. An individual was considered a member of a household if he/she had slept within that compound for at least six of the preceding twelve months. Household members who had died in the past 30 days were also included, as they might have had an episode of RI.

Once written informed consent had been obtained, the recognized heads of households were interviewed. If the household head was not available or was unable to answer the questionnaire, the next most senior adult in the same household was interviewed instead. A pre-designed, structured questionnaire covering socio-demographic information, RI in household members, healthcare-seeking behavior, and household and animal care practices, was used to collect information. The questionnaire was designed in consultation with experts from the CDC International Emerging Infections Program and the National Centre for Immunizations and Respiratory Diseases, Influenza Division. The interviews were conducted in Lao and, when needed, a translator helped with the translation of local dialects.

Sixteen focus group discussions (FGDs) were conducted (eight in each urban and rural area). The participants in the qualitative study were recruited from those who took part in the questionnaire interviews. Eligible participants were selected purposively based on their having at least one family member who had had RI symptoms at least once during last month and their willingness to participate. There were seven to eleven participants per FGD with varying occupations, ages and educational backgrounds. Each FGD lasted approximately 1-1.5 hours and was tape-recorded. Translators were used to conduct FGDs with some ethnic minority women in rural areas. The tapes and notes of the FGDs were transcribed into Lao and then translated into English.

Written informed consent was obtained from all participants before the interviews and FGDs. Ethical clearance for the study was granted by the Ethics Committee of the University of Health Sciences, Ministry of Health of Laos.

\section{Sample size determination}

Assuming that $2.2 \%$ of all individuals would have had an episode of RI in the 30 days preceding the assessment [7] with an alpha of 0.05 and estimated precision of $1 \%$, a sample size of 865 households was needed. The calculated sample size was, however, adjusted for a design effect of 2.0 to account for correlations within clusters; therefore we aimed to include a total of 1,752 households.

\section{Data analysis}

Quantitative data were analyzed using Stata v9 (StataCorp, College Station, TX, USA). Comparisons between two groups were made using Chi-square, Fisher's Exact, Student-t, and Mann-Whitney $U$ tests as appropriate. Multiple logistic regression analysis was performed to identify factors associated with RI and RI seeking healthcare. All variables with $P$-values $<0.05$ in univariate analysis were included in the multiple logistic regression model and this was processed using the backward stepwise method. Qualitative data were analyzed using a participatory process in parallel with software-based analysis using MAXQED. Transcripts were read and reread and open codes were developed to capture emerging themes in the data. Then the key themes and concepts from the English transcripts were identified. The themes were systematically catalogued across all focus groups. A description of how the themes were described and explained by the FGD participants was then made. Finally, the themes were compared across major subgroups of participants.

\section{Results}

Of all 1,872 households and 9,703 villagers in the target study sites, 1,751 (93.5\%) and 9,114 (94\%) respectively were included in the study (Figure 2). The reasons for non-recruitment were that the household members were not in the villages during the survey or had moved away.

\section{Socio-economic and demographic characteristics of study households and population}

Of the study population, $50 \%$ were males, $72 \%$ were from peri-urban areas, and 59\% were Lao Loom (Table 1). The median (IQR) age of all study villagers was 23 (11-39) years and this was significantly lower in rural [17 (8-32)] compared with peri-urban $[25(13-41)]$ areas $(\mathrm{p}<0.001)$. Thirty-four percent of the study population were children $\leq 15$ years and $10 \%$ were aged $<5$ years. The overall median (IQR) highest number of schooling years in the households was 10 (5-11) and this was statistically lower in the rural [5 (2-5)] than in the peri-urban [11 (8-11)] areas $(\mathrm{p}<0.001)$. Overall, $62 \%$ of the study population were 


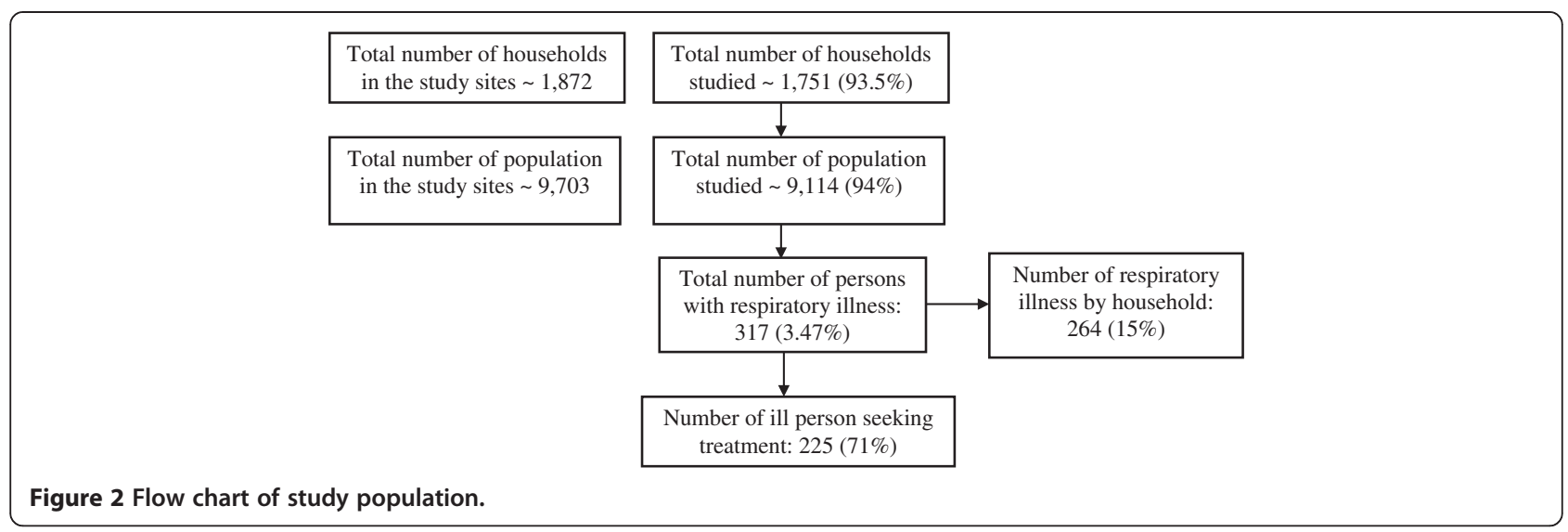

classified as poor and the proportion of the study population classified as poor was significantly higher in rural than in peri-urban areas $(\mathrm{p}<0.001)$ (Table 1$)$. The overall mean (95\% CI) number of bedrooms in the households was 2.2 (2.1-2.3) and 98\% of all households used wood/ charcoal stoves for cooking. The mean (95\% CI) number of household members who smoked inside the house was 1.5 (1.4-1.6).

\section{Respiratory illness burden and disease severity, and factors associated with RI}

The overall proportions of persons and households with RI during the 30 days before interview were $3.5 \%$ (317/ $9,114)$ and $15 \%(264 / 1,751)$, respectively (Table 2$)$. The percentage of persons who had had RI was significantly higher in rural (6.2\%) than in peri-urban (2.4\%) areas $(\mathrm{p}<0.001)$ (Table 1). This figure corresponds to $10.6 \%$ (91/855) for Sekong, 4.0\% (70/1,727) for Xayabouli, $2.8 \%$ $(100 / 3,611)$ for Vientiane Capital, and $1.9 \%(56 / 2,921)$ for Vientiane Province $(\mathrm{p}<0.001)$. The proportion of persons with RI was significantly lower in Lao Loom than in non-Lao Loom groups [143/5,346 (2.7\%) vs 174/3,768 (4.6\%), $P<0.001]$. The proportion of the persons with RI among specific ethnic groups was 12.6\% (42/332) for Alak, 10.1\% (27/268) for Dakkang, 8.6\% (22/254) for Taliang, $4.1 \%(70 / 1,741)$ for Prai, $2.7 \%(143 / 5,346)$ for Lao Loom, and $1.1 \%(13 / 1,168)$ for Hmong $(\mathrm{p}<0.001)$. The overall median (IQR) age of ill people was 17 (5 - 40) years: $48.5 \%$ of them were children $\leq 15$ years and $24 \%$ were children under five. The percentage of people who had suffered from RI was $2.7 \%(168 / 6,246)$ among persons aged $\geq 15$ years, $3.7 \%(72 / 1,930)$ for those aged $5-14$ years, and $8.2 \%(77 / 938)$ for children $<5$ years $(\mathrm{p}<0.001)$. There was no difference in RI frequency between males $[3.7 \%(168 / 4,543)$ and females $[3.3 \%(149 / 4,571)](\mathrm{p}=0.25)$.

Among those who were reported to have been ill, 219 (69\%), 77 (24\%), and 21 (7\%) of illnesses were classified as mild (no disturbance in daily activities), moderate (some daily activities limited), and severe (cannot work or do daily activities), respectively, and 8 (3.5\%) were admitted to hospital, with a median (IQR) number of days in hospital of $4.0(2.5-4.5)$. The overall median (IQR) duration of the illness was 4 (3-7) days. Fever (100\%), cough (90\%) and sore-throat (83\%) were the main symptoms reported, followed by runny nose (70\%), headache (65\%), muscle ache (58\%), difficult or fast breathing (42\%), chills (30\%), wheezing (21\%), and nausea or vomiting (18.5\%) (Table 3 ).

The disease severity was not significantly different between children and adults $(\mathrm{p}=0.35)$. With the exception of muscle pain, which was significantly more frequent in adults $(66 \%)$ compared to children $(49 \%)(\mathrm{p}=0.005)$, other symptoms and signs were similar between the groups. The median (IQR) number of days of illness was also significantly greater in adults than in children [5 (3-7) vs 4 (3-7), $P=0.02$ ].

Of 229 adults with RI, 143 (62\%) had been absent from their daily work during their illness and $65 \%$ of their family members had also been absent from their daily activities in order to look after them.

Factors associated with RI are shown in Table 4. In a multiple logistic regression analysis, factors significantly related to RI were children $<5$ years, people living in Sayabouli and Sekong, and a very smoky environment inside the house (Table 5).

\section{Treatment seeking behavior and preference, and factors associated with RI seeking healthcare}

Of all villagers with RI, 225 (71\%) sought treatment [94\% in peri-urban and $48 \%$ in rural areas $(\mathrm{p}<0.001)$ ] (Table 2$)$. The percentage of persons with RI who sought treatment among each ethnic group was 95\% (136/143) for Lao Loom, 85\% (11/13) for Hmong, 74\% (31/42) for Alak, 41\% (9/22) for Taliang, 41\% (11/27) for Dakkang, and 39\% (27/ 70) for Prai $(\mathrm{p}<0.001)$. Sick persons in Vientiane Capital [98\% (98/100)] and in Vientiane Province [87.5\% (49/56)] sought treatment more often than those from Sekong [56\% (51/91)] and Xayabouli [39\% (27/70)], $(\mathrm{p}<0.001)$. 
Table 1 Socio-demographic characteristics of the study population $^{\dagger}$

\begin{tabular}{|c|c|c|c|c|}
\hline Variable & Total & $\begin{array}{c}\text { Peri-urban } \\
\text { (VT Capital \& } \\
\text { Province) }\end{array}$ & $\begin{array}{c}\text { Rural } \\
\text { (Xekong \& } \\
\text { Xayabuli } \\
\text { Provinces) }\end{array}$ & $p$-value \\
\hline Households studied & $1,751(100)$ & $1,330(76)$ & $421(24)$ & - \\
\hline People studied & $9,114(100)$ & $6,532(72)$ & $2,582(28)$ & - \\
\hline $\begin{array}{l}\text { Villagers who died } \\
\text { during the } 30 \text { days } \\
\text { before interview }\end{array}$ & $7(0.07)$ & $5(0.076)$ & $2(0.077)$ & 0.99 \\
\hline Female & $4,571(50)$ & $3,243(50)$ & $1,328(51)$ & 0.12 \\
\hline $\begin{array}{l}\text { Median (IQR) } \\
\text { age (years) }\end{array}$ & $23(11-39)$ & $25(13-41)$ & $17(8-32)$ & $<0.001$ \\
\hline Adult $>15$ years & $6,021(66)$ & $4,643(71)$ & $1,378(53)$ & $<0.001$ \\
\hline Children $\leq 15$ years & $3,093(34)$ & 1,889 (29) & $1,204(47)$ & \\
\hline Children $<5$ years & $938(10)$ & $554(8)$ & $384(15)$ & $<0.001$ \\
\hline $\begin{array}{l}\text { Median (IQR) highest } \\
\text { schooling years in } \\
\text { household }\end{array}$ & $10(5-11)$ & $11(8-11)$ & $5(2-5)$ & $<0.001$ \\
\hline \multicolumn{5}{|l|}{ Ethnicity } \\
\hline - Lao Loom & $5,346(59)$ & $5,334(82)$ & $12(0.5)$ & $<0.001$ \\
\hline - Hmong & 1,168 (13) & $1,166(18)$ & $2(0.08)$ & \\
\hline - Prai & $1,714(19)$ & 0 & $1,714(66)$ & \\
\hline - Alak & $332(4)$ & 0 & $332(13)$ & \\
\hline - Taliang & $254(3)$ & 0 & $254(10)$ & \\
\hline - Dakkang & $268(3)$ & $1(0.01)$ & $267(10)$ & \\
\hline - Mixed & $5(0.1)$ & 0 & $5(0.2)$ & \\
\hline - Others & $27(0.3)$ & $1(0.01)$ & $26(1)$ & \\
\hline \multicolumn{5}{|l|}{ Wealth index* } \\
\hline - Poorest & 2,098 (23) & $29(0.5)$ & $1,797(70)$ & $<0.001$ \\
\hline - Second & $1,824(20)$ & $1,043(16)$ & $781(30)$ & \\
\hline - Middle & $1,730(19)$ & $1,825(28)$ & $1(0.04)$ & \\
\hline - Fourth & 1,735 (19) & $1,815(28)$ & $3(0.1)$ & \\
\hline - Richest & 1,727 (19) & $1,820(28)$ & 0 & \\
\hline
\end{tabular}

${ }^{\dagger}$ Data shown as number (\%) unless indicated.

* Principal components analysis was performed by using information on the ownership of household goods and amenities (assets) to assign weights to each household asset and obtain wealth scores for each household in the sample. The assets used in these calculations were as follows: electricity, clock, radio, electric fan, mattress, black and white television, color television, CD/ VCD player, water pump, bed, DVD player, satellite, mobile telephone, telephone, refrigerator, air conditioner, washing machine, sofa, watch, bicycle, oxcart, motorbike, tractor, tuk-tuk, car/truck, engine boat, type of poorest quintile to the richest quintile, based on the wealth scores of households they were living in. The wealth index is assumed to capture the underlying longterm wealth through information on the household assets, and is intended to produce a ranking of households by wealth, from poorest to richest. The wealth index does not provide information on absolute poverty, current income or expenditure levels, and the wealth scores calculated are applicable for only the particular data set they are based on. Further information on the construction of the wealth index can be found in Rutstein and Johnson, 2004, and Filmer and Pritchett, 2001.
The first treatment places/health providers chosen by these people were private clinics $(29 \%)$, health centres (19.5\%), pharmacies (15\%), village health volunteers (15\%), district hospitals (5\%), central hospitals (4\%), provincial hospitals (3.5\%), and mobile clinics (1.3\%). A small proportion $(1.4 \%)$ of these people went to see traditional or spiritual healers as the first choice for their illnesses. Lao Loom were likely to seek treatment at private clinics $(47 \%)$ and pharmacies $(21 \%)$ while nonLao Loom preferred to go to health centres (39\%) and to see village health volunteers $(37 \%)(\mathrm{p}<0.001)$.

The most frequent reasons given for selecting these places/health providers as the first choice were that: it was close to their house (70\%); they had previously had good experiences at those facilities/health providers (36\%); it was cheap (29\%); it provided the appropriate service for their illness (25\%); it offered a good quality of care (19\%); and that waiting times were short at the facility (19\%).

The median (IQR) traveling time, regardless of transportation mode, from patients' homes to health facilities was 5 (4.5-20) minutes. The most common modes of transport used by sick people to get to the health facilities were walking (44.8\%) and motorcycle (43.9\%). Eighty-two percent $(260 / 317)$ of the people who sought treatment were prescribed medication and were able to afford the treatment, while $16 \%$ of them could not afford the medicines prescribed by the healthcare providers. The median (IQR) cost of care during their illnesses was LAK 20,000 $(10,000-60,000)$ or $\sim 2.5(1.25-7.5)$ US\$.

Factors associated with RI treatment-seeking are shown in Table 6. In a multi-variate analysis, only peri-urban residence was independently correlated with seeking care for RI $(\mathrm{OR}=17.9 ; 95 \% \mathrm{CI}=8.4-37.9, \mathrm{p}<0.001)$ (Table 7).

Among those who did not seek treatment, 38\% thought their illnesses were just mild and would be self-limiting, and $33 \%$ of them said they were not able to afford the treatment and transportation costs. More than half (59\%) of the villagers who did not seek care said they only took rest at home, while $31.5 \%$ of them self-medicated at home $[55.5 \%$ in peri-urban and $29 \%$ in rural areas $(\mathrm{p}<0.001)]$. The reasons for not seeking care were not significantly different between Lao Loom and non-Lao Loom ethnicities.

\section{Comparison of treatment-seeking between peri-urban and rural areas}

Fewer sick persons sought care in rural $(48 \%)$ than periurban $(94 \%)$ areas $(\mathrm{p}<0.001)$ as they tended to rest at home more often than those in the urban-areas $(63 \%$ vs $22 \%, \mathrm{p}=0.04)$. There were no statistically significant differences in the reasons for not seeking care between the sick people who lived in rural and peri-urban areas. 
Table 2 Information on RI and treatment seeking among the study population ${ }^{\dagger}$

\begin{tabular}{|c|c|c|c|c|}
\hline Variable & Total & $\begin{array}{c}\text { Peri-urban } \\
\text { (VT Capital \& Province) } \\
\end{array}$ & $\begin{array}{c}\text { Rural } \\
\text { (Xekong \& Xayabuli Provinces) }\end{array}$ & p-value \\
\hline Households with RI & $264(15)$ & $133(10)$ & $131(31)$ & $<0.001$ \\
\hline Persons with Rl & $317(3.5)$ & $156(2.4)$ & $161(6.2)$ & $<0.001$ \\
\hline Median (IQR) age (years) of persons with RI $(n=317)$ & $17(5-40)$ & $13(4-37)$ & $20(5-41)$ & 0.23 \\
\hline \multicolumn{5}{|l|}{ Age group of persons with $\mathrm{Rl}$} \\
\hline - Adult > 15 years & $163(51.5)$ & $70(45)$ & $93(58)$ & \multirow[t]{2}{*}{0.02} \\
\hline - Children $\leq 15$ years & $154(48.5)$ & $86(55)$ & $68(42)$ & \\
\hline - Children $<5$ years & $77(24)$ & $41(26)$ & $36(22)$ & 0.42 \\
\hline - Elderly (> 65 years) & $5(2)$ & $5(3)$ & $5(3)$ & 0.96 \\
\hline \multicolumn{5}{|l|}{ Rl by ethnic groups } \\
\hline - Lao Loom & $143(45)$ & $143(92)$ & 0 & \multirow[t]{6}{*}{$<0.001$} \\
\hline - Hmong & $13(4)$ & $13(8)$ & 0 & \\
\hline - Prai & $70(22)$ & 0 & $70(43)$ & \\
\hline - Alak & $42(13)$ & 0 & $42(26)$ & \\
\hline - Taliang & $22(7)$ & 0 & $22(14)$ & \\
\hline - Dakkang & $27(8.5)$ & 0 & $27(17)$ & \\
\hline \multicolumn{5}{|l|}{ Persons with RI who sought treatment } \\
\hline - Overall & $225(71)$ & $147(94)$ & $78(48)$ & $<0.001$ \\
\hline - Lao Loom & $136(60)$ & $136(92)$ & 0 & \multirow[t]{6}{*}{$<0.001$} \\
\hline - Hmong & $11(5)$ & $11(8)$ & 0 & \\
\hline - Prai & $27(12)$ & 0 & $27(35)$ & \\
\hline - Alak & $31(14)$ & 0 & $31(40)$ & \\
\hline - Taliang & $9(4)$ & 0 & $9(11)$ & \\
\hline - Dakkang & $11(5)$ & 0 & $11(14)$ & \\
\hline
\end{tabular}

${ }^{\dagger}$ Data shown as number (\%) unless indicated.

Table 3 Symptoms and signs by level of illness ${ }^{\dagger}$

\begin{tabular}{|c|c|c|c|c|}
\hline \multirow[t]{3}{*}{ Symptoms and signs } & \multicolumn{3}{|c|}{ Level of illness $^{\S}$} & \multirow[t]{3}{*}{$\mathrm{p}$-value } \\
\hline & Mild & Moderate & Severe & \\
\hline & $n=219$ & $\mathrm{n}=77$ & $\mathrm{n}=\mathbf{2 1}$ & \\
\hline Fever & $219 / 219(100)$ & $76 / 76(100)$ & $21 / 21(100)$ & 1.00 \\
\hline Chills & $48 / 212(22.6)$ & 29/76 (38.1) & 16/21 (76.1) & $<0.001$ \\
\hline Headache & 119/191 (62.3) & $53 / 71(74.6)$ & $13 / 21(61.9)$ & 0.16 \\
\hline Sore throat & 168/199 (84.4) & $56 / 72(77.7)$ & 18/21 (85.7) & $0.41^{*}$ \\
\hline Runny nose & $165 / 217(76.04)$ & 40/77 (51.9) & $16 / 21(76.1)$ & $<0.001$ \\
\hline Cough & 192/219 (87.6) & $72 / 77(93.5)$ & $20 / 21(95.2)$ & $0.32^{*}$ \\
\hline Muscle aches & $111 / 188(59.04)$ & $37 / 71(52.1)$ & $16 / 21(76.1)$ & 0.14 \\
\hline Difficult or fast breathing & 78/208 (37.5) & $32 / 75(42.6)$ & 17/21 (80.9) & 0.001 \\
\hline Wheezing & 39/211 (18.4) & 15/75 (20) & $10 / 21(47.6)$ & $0.01^{*}$ \\
\hline Decreased daily activity & $64 / 207(30.9)$ & $39 / 75(52)$ & $15 / 20(75)$ & $<0.001$ \\
\hline Nausea or vomiting & $32 / 216(14.8)$ & $21 / 75(28)$ & $5 / 21(23.8)$ & $0.03^{*}$ \\
\hline
\end{tabular}

${ }^{\dagger}$ Data shown as number (\%) unless indicated.

* Fisher's exact test.

${ }^{\S}$ Symptoms and signs were classified as mild if there was no disturbance in people's daily activities, as moderate if some daily activities were limited, and as severe if they were not able to work or do daily activities. 
Table 4 Factors associated with respiratory infection (RI)

\begin{tabular}{|c|c|c|c|c|c|}
\hline \multirow[t]{3}{*}{ Variable } & \multicolumn{2}{|c|}{ RI } & \multirow[t]{3}{*}{ p-value } & \multirow[t]{3}{*}{ OR } & \multirow[t]{3}{*}{$95 \% \mathrm{Cl}$} \\
\hline & Yes n (\%) & No $n(\%)$ & & & \\
\hline & $N=317$ & $N=8,797$ & & & \\
\hline Sex: - Male & $168(53)$ & $4,375(50)$ & & 1 & \\
\hline - Female & $149(47)$ & $4,422(50)$ & 0.25 & 0.9 & $0.7-1.1$ \\
\hline Ethnic group: - Lao Loom & $143(45)$ & $5,203(59)$ & & 1 & \\
\hline - Hmong & $13(4)$ & $1,155(13)$ & $<0.001$ & 2.4 & $1.9-3.0$ \\
\hline - Other ethnic groups & $161(51)$ & $2,439(28)$ & 0.002 & 0.4 & $0.2-0.7$ \\
\hline Age group (years): $<5$ & $77(24)$ & $861(10)$ & $<0.001$ & 3.2 & $2.4-4.3$ \\
\hline $5-14$ & $72(23)$ & $1,858(21)$ & 0.01 & 1.4 & $1.0-1.8$ \\
\hline$\geq 15$ & $168(53)$ & $6,078(69)$ & & 1 & \\
\hline Location: - Vientiane Capital & $100(31)$ & $3,511(40)$ & & 1 & \\
\hline - Vientiane Province & $56(18)$ & $2,865(33)$ & 0.03 & 0.6 & $0.4-0.9$ \\
\hline - Sayabouli & $70(22)$ & 1,657 (19) & 0.01 & 1.4 & $1.1-2.0$ \\
\hline - Sekong & $91(29)$ & $764(7)$ & $<0.001$ & 4.2 & $3.1-5.6$ \\
\hline Wealth index: - Low & $209(66)$ & $4,821(55)$ & 0.08 & 1.3 & $0.9-1.8$ \\
\hline - Moderate & $61(19)$ & $2,526(29)$ & 0.13 & 0.7 & $0.5-1.1$ \\
\hline - High & $47(15)$ & $1,450(16)$ & & 1 & \\
\hline \multicolumn{6}{|l|}{ Household head education level: } \\
\hline - Primary school & $136(43)$ & $2,567(29)$ & $<0.001$ & 2.2 & $1.5-3.3$ \\
\hline - Secondary school & $146(46)$ & $4,718(54)$ & 0.12 & 1.3 & $0.9-1.9$ \\
\hline - College/university & $35(11)$ & $1,512(17)$ & & 1 & \\
\hline \multicolumn{6}{|l|}{ Smoky environment inside house: } \\
\hline - No stove inside & $77(24)$ & $3,458(39)$ & 0.01 & 0.6 & $0.4-0.9$ \\
\hline - No smoke & $44(14)$ & $1,249(14)$ & & 1 & \\
\hline - Some smoke & $92(29)$ & $2,736(31)$ & 0.80 & 0.9 & $0.6-1.3$ \\
\hline - Very smoky & $104(33)$ & $1,354(15)$ & $<0.001$ & 2.1 & $1.5-3.1$ \\
\hline \multicolumn{6}{|c|}{ Animal slaughtering in the past 30 days in household: } \\
\hline$-\mathrm{No}$ & $238(75)$ & $6,547(74)$ & & 1 & \\
\hline - Yes (without protection) & $8(3)$ & $169(2)$ & 0.47 & 1.3 & $0.6-2.6$ \\
\hline - Yes (with protection) & $71(22)$ & $2,081(23)$ & 0.64 & 0.9 & $0.7-1.2$ \\
\hline \multicolumn{6}{|c|}{ Butchering and cooking animal in the past 30 days in household: } \\
\hline$-\mathrm{No}$ & $111(35)$ & $2,278(26)$ & & 1 & \\
\hline - Yes (without protection) & $4(1)$ & $114(1)$ & 0.52 & 0.7 & $0.2-1.9$ \\
\hline - Yes (with protection) & $202(64)$ & $6,405(73)$ & $<0.001$ & 0.6 & $0.5-0.8$ \\
\hline \multicolumn{6}{|c|}{ Animal died in the past 30 days in household: } \\
\hline - No animal in household & $49(15)$ & $1,722(20)$ & & 1 & \\
\hline - No animal died & $232(73)$ & $6,554(74)$ & 0.17 & 1.2 & $0.9-1.7$ \\
\hline - Animal died & $36(11)$ & $521(6)$ & $<0.001$ & 2.4 & $1.5-3.7$ \\
\hline
\end{tabular}

Sick people who lived in peri-urban areas commonly chose private clinics $(44.9 \%)$ or pharmacies $(22.5 \%)$ as the first places of care while those who lived in rural areas frequently chose to consult with the village health volunteer $(42.3 \%)$ or visit the health centre $(41.1 \%)$ as their first choice $(\mathrm{p}<0.001)$. This difference was due to the fact that there were more private clinics and pharmacies in peri-urban than in rural areas.

Quality of care $(26 \%$ vs $6 \%, \mathrm{p}<0.001)$, having good previous experience at the facilities $(43.5 \%$ vs $5 \%, \mathrm{p}=0.01)$, familiarity with healthcare providers $(16 \%$ vs $5 \%, \mathrm{p}=0.01)$, and short waiting times ( $28 \%$ vs $1 \%, \mathrm{p}<0.001)$, were 
Table 5 Multiple logistic regression analysis of factors associated with RI

\begin{tabular}{|c|c|c|c|}
\hline Variable & OR & $95 \% \mathrm{Cl}$ & $\mathrm{p}$-value \\
\hline Being ethnic Hmong & 0.4 & $0.2-0.8$ & 0.01 \\
\hline Being others ethnicities & 0.8 & $0.1-4.6$ & 0.84 \\
\hline Aged $<5$ years & 2.7 & $2.1-3.7$ & $<0.001$ \\
\hline Aged $5-14$ years & 1.2 & $0.9-1.7$ & 0.08 \\
\hline Living in Vientiane Province & 0.9 & $0.6-1.3$ & 0.61 \\
\hline Living in Sayabouli & 1.6 & $1.1-2.6$ & 0.03 \\
\hline Living in Sekong & 4.1 & $2.5-6.8$ & $<0.001$ \\
\hline $\begin{array}{l}\text { Education of household head } \\
\text { of primary school }\end{array}$ & 0.7 & $0.5-1.1$ & 0.07 \\
\hline No stove inside the house & 0.5 & $0.4-0.8$ & 0.004 \\
\hline Very smoky environment in the house & 1.8 & $1.3-2.7$ & $<0.001$ \\
\hline $\begin{array}{l}\text { Butchering and cooking animal in the } \\
\text { past } 30 \text { days in household with protection }\end{array}$ & 1.2 & $0.8-1.5$ & 0.28 \\
\hline $\begin{array}{l}\text { Animal died in household in the } \\
\text { past } 30 \text { days }\end{array}$ & 1.01 & $0.6-1.7$ & 0.95 \\
\hline
\end{tabular}

reasons given significantly more often in peri-urban than in the rural areas for choosing the first places of treatment. More sick people in rural areas walked to the health facility than those in peri-urban areas ( $94 \%$ vs $17 \%$, $\mathrm{p}<0.001)$, but more villagers in the peri-urban areas used motorcycles as their mode of transport when compared with those who lived in rural areas (68\% vs $2.4 \%, \mathrm{p}<0.001$ ). The median (IQR) traveling time (in minutes) from the place of residence to the first place of treatment was significantly shorter in rural [5 (3 - 15)] than in periurban $[5(5-20)]$ areas $(\mathrm{p}=0.01)$. After seeking care, all patients $(100 \%)$ in peri-urban areas received medication, while $95 \%$ of the patients in rural area did so $(\mathrm{p}=0.01)$.

The proportion of sick persons who could not afford treatment was also higher in rural (37\%) compared to peri-urban areas $(4 \%)(\mathrm{p}<0.001)$, and the median $(\mathrm{IQR})$ cost of medication paid by the patients was significantly higher in the peri-urban $[30,000(15,000-80,000)$ LAK or $\sim 3.75(1.87-10.0)$ US\$] than in the rural areas $[10,000$ $(5,000-30,000)$ LAK or $1.25(0.62-3.75)$ US\$] $(\mathrm{p}<0.001)$.

Table 6 Factors associated with respiratory infection (RI) healthcare seeking

\begin{tabular}{|c|c|c|c|c|c|}
\hline \multirow[t]{3}{*}{ Variable } & \multicolumn{2}{|c|}{ Seeking care } & \multirow[t]{3}{*}{$P$-value } & \multirow[t]{3}{*}{ OR } & \multirow[t]{3}{*}{$95 \% \mathrm{Cl}$} \\
\hline & Yes n (\%) & No n (\%) & & & \\
\hline & $N=225$ & $\mathrm{~N}=92$ & & & \\
\hline Male & $119(53)$ & $49(53)$ & 0.95 & 1 & \\
\hline Female & $106(47)$ & $43(47)$ & & 1.01 & $0.6-1.6$ \\
\hline Lao Loom & $136(60)$ & $7(8)$ & $<0.001$ & 20.6 & $9.1-46.9$ \\
\hline Hmong & $11(5)$ & $2(2)$ & 0.02 & 5.8 & $1.2-27.2$ \\
\hline Others & $78(35)$ & $83(90)$ & & 1 & \\
\hline Aged $<5$ & $56(25)$ & $21(23)$ & 0.55 & 1.2 & $0.6-2.2$ \\
\hline Age 5-14 & $53(23)$ & $19(21)$ & 0.47 & 1.2 & $0.6-2.3$ \\
\hline Age $\geq 15$ & $116(52)$ & $52(56)$ & & 1 & \\
\hline Vientiane Capital & $98(43)$ & $2(2)$ & $<0.001$ & 38.4 & $8.9-165.4$ \\
\hline Vientiane Province & $49(22)$ & $7(8)$ & $<0.001$ & 5.4 & $2.2-13.4$ \\
\hline Sayabouli & $27(12)$ & $43(47)$ & 0.02 & 0.5 & $0.2-0.9$ \\
\hline Sekong & $51(23)$ & $40(43)$ & & 1 & \\
\hline \multicolumn{6}{|l|}{ Wealth index: } \\
\hline - Low & $121(54)$ & $88(96)$ & & 1 & \\
\hline - Moderate & $60(27)$ & $1(1)$ & $<0.001$ & 43.6 & $5.9-320.8$ \\
\hline - High & $44(19)$ & $3(3)$ & $<0.001$ & 10.6 & $3.2-35.5$ \\
\hline \multicolumn{6}{|c|}{ Education level of head of household: } \\
\hline - Primary school & $79(35)$ & $57(62)$ & & 1 & \\
\hline - Secondary school & $113(50)$ & $33(36)$ & 0.001 & 2.4 & $1.5-4.1$ \\
\hline - College/university & $33(15)$ & $2(2)$ & 0.001 & 11.9 & $2.7-51.6$ \\
\hline \multicolumn{6}{|l|}{ Disease severity: } \\
\hline - Mild & $161(72)$ & $58(63)$ & & 1 & \\
\hline - Moderate & $50(22)$ & $27(29)$ & 0.15 & 0.6 & $0.3-1.2$ \\
\hline - Severe & $14(6)$ & 7 (8) & 0.50 & 0.7 & $0.3-1.8$ \\
\hline
\end{tabular}


Table 7 Multivariate logistic regression analysis of factors associated with RI healthcare seeking

\begin{tabular}{llll}
\hline Variable & OR & $\mathbf{9 5 \%} \mathbf{C l}$ & p-value \\
\hline Being ethnic Hmong & 0.5 & $0.08-3.5$ & 0.57 \\
Living in Vientiane Province & 0.1 & $0.02-0.9$ & 0.04 \\
Living in Sayabouli & 0.007 & $0.001-0.05$ & $<0.001$ \\
Living in Sekong & 0.01 & $0.001-0.09$ & $<0.001$ \\
Residence in peri-urban area & 17.9 & $8.4-37.9$ & $<0.001$ \\
Family with low wealth index & 0.3 & $0.08-1.5$ & 0.18 \\
$\begin{array}{l}\text { Household head education level of } \\
\text { primary school }\end{array}$ & 8.5 & $1.1-66.1$ & 0.44 \\
Household head education level of & 2.2 & $0.3-14.3$ & 0.39 \\
secondary school & & & \\
\hline
\end{tabular}

The percentage of sick persons who smoked cigarettes was significantly higher in the rural compared to the peri-urban areas [78/156 (50\%) vs 9/161 (6\%), p<0.001)].

\section{Qualitative data on healthcare-seeking behavior}

Sixteen focus group discussions (FGDs) were conducted (see above) to explore people's healthcare-seeking behavior when they had RI. The order of seeking care, and different factors that influenced sick persons as they progressed along a continuum of care, were mapped (Figure 3). In general, all participants first attempted to self-treat any illness at home. Some experiences of selftreatment, such as drinking hot water, taking a sponge bath, self-medication (especially with medical herbs), were documented. More rural than peri-urban participants reported self-treatment. The main reasons given for self-treatment were convenience, lower treatment cost, and the fact that the illness was mild. An example of a comment from one FGD was: "If there is someone in the household who got sick, if they got sick and they were not severely unwell, they went to buy medicine by themselves. If the illness is severe, they asked someone to buy medicines for them." (Female, age 18-30 year old; northern Xayabouli province).

The decision to move from one provider to another (or from self-treatment to seeking some form of treatment) was commonly influenced by the severity of the illness, treatment failure or a lack of improvement, and a lack of medicines. Rural areas were considered by FGD participants as being characterized by constrained access, in terms of infrastructure and distance, together with higher direct and indirect costs of seeking care. Because of these barriers, participants stated that they would seek formal healthcare (e.g. health centre, hospitals) only when they were very ill, unlike their counterparts in urban areas, who seek informal care (e.g. pharmacies) even in cases of very mild illness. Given the higher costs and constrained access, participants in rural areas tended to revert to whatever providers were locally available for treatment of their illness. These participants often used village health volunteers, but also turned to illegal physicians (unregistered providers of medicine and health advice), spiritual healers, traveling salesmen, or self-treatment with herbal medicines in equal numbers. Other than specific cultural beliefs about spiritual healers held by a small number of participants, these 'informal' healthcare options were not preferred in rural areas, but were used as the only option available because all other options were too expensive and too far away. When people in remote, rural areas say they have "sought treatment", the type and quality of treatment available is quite different from that available to those in peri-urban or less remote settings. Availability of service

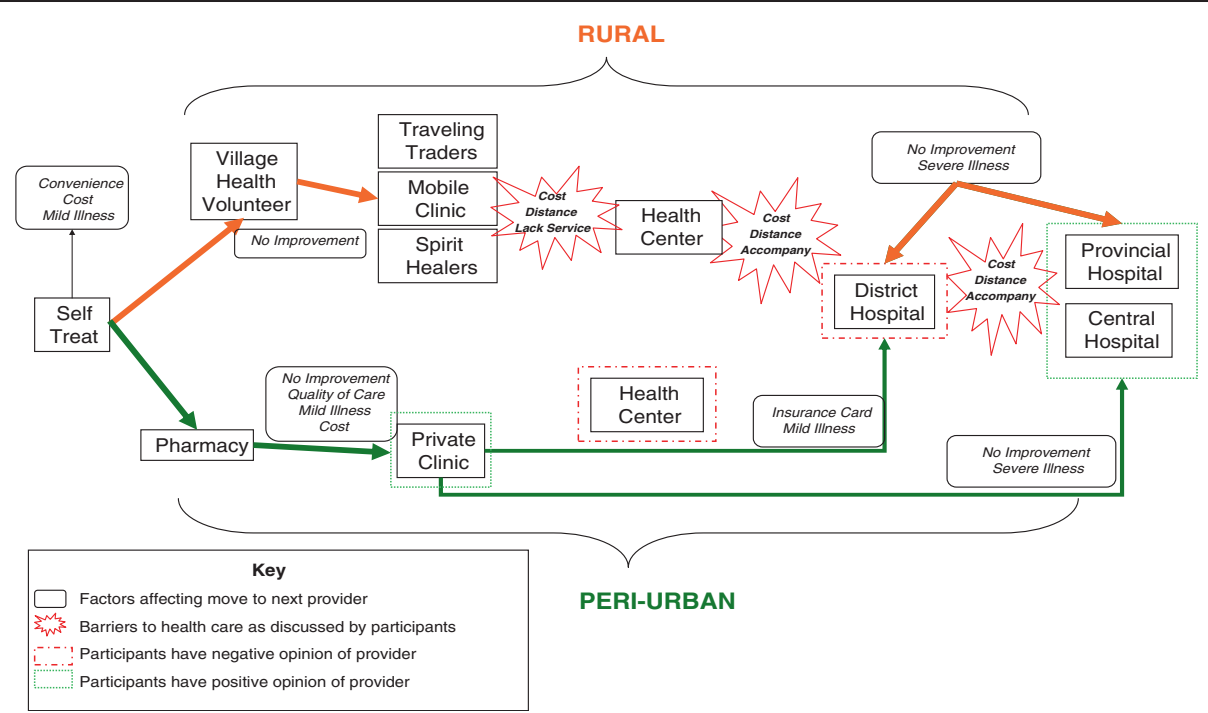

Figure 3 Process mapping of health seeking behaviors in rural and peri-urban areas. 
providers in rural areas was also much more constrained. Village health volunteers (VHVs) and health centres would sometimes not have the medicines needed; furthermore the equipment and acceptability of care at each place was considered inadequate by some participants.

Cost, distance, and service availability were the primary factors acting as barriers to participants in rural areas accessing formal health services, while cost, service availability and trust were important factors relating to using other types of healthcare providers. Rural participants were less likely to be able to seek any kind of formal healthcare for illness. Clearly those in urban areas have many more options from which to choose, and thus have more ways of comparing different options and choosing where to seek care. They are more likely to receive some form of treatment than those in rural areas. While central hospitals are considered very expensive, most participants in Vientiane municipality would still seek care there if they had a severe illness. Furthermore when cost is similar for two or more options, those in urban areas look to quality and the range of services offered in order to decide which to choose. There are more options and alternative forms of care in urban areas, so that if one option (e.g. central hospital) is too expensive, there are many other possible choices, such as private clinics, provincial hospitals, and district hospitals, especially if the patient has insurance. As a participant in one FGD mentioned: "Going to the district hospital is more complicated with many steps. I do not like to go there. Seeing doctors at the private clinic is better because it is the same doctor as in the district hospital while the cost is 25,000 LAK 3.12 US\$." (Female, 18-30 years, Vientiane capital).

\section{Discussion}

This is the first study on the burden of, and the healthcare-seeking behavior for, RI conducted in Laos. The prevalence of RI in the survey was higher than the prevalence of influenza in rural Thailand (2.2\%) [7] and might have been higher if the survey had been carried out during the winter. The Lao national health survey in 2000 revealed that $\sim 1 \%$ of children under-five had had acute respiratory infection in the two weeks before the survey [4]. Indoor air pollution (i.e. a very smoky environment inside the household) was a significant risk factor for the high prevalence of RI found in the present study. Many households, particularly in rural areas, used firewood/charcoal for cooking inside their houses, some of which had only a single room. The proportion of persons with RI in the present survey was significantly higher in rural than in peri-urban areas, probably due to the younger age of the study population and the poorer socioeconomic, environmental and hygienic conditions in the rural areas, a finding that is consistent with previous studies [8-11]. Childhood immunization coverage, which is usually higher in peri-urban than in rural areas, may also play an important role in reducing the risk of respiratory illness among peri-urban people.

About two-thirds of the people with RI in this study sought treatment, which was a high proportion but similar to that found in previous studies from Sri Lanka, Nigeria, Bangladesh, and Uganda [12-16]. In the Lao national health survey in 2000 , only $47 \%$ of people who had suffered from any illnesses in the two weeks preceding the survey had sought care [4]. Whether sick people seek care depends on disease severity, distance from home to healthcare facilities, availability of care services, and affordability. Severity of illness could not explain the high percentage of healthcare-seeking in the present study because only $6 \%$ of sick persons were classified as having severe disease and the proportion of ill people who sought care was similar among those who had mild, moderate, and severe disease. The high rate of healthcare-seeking of people in the present study might be due to the availability of healthcare services close to their own homes i.e. in their own village. In the national health survey in 2000, the reasons for not seeking care given by the villagers were mild illness, lack of transport, long distance, and cost [4]. The reasons for not seeking care in our survey were inability to afford treatment, transportation, and a perception that their illness was mild. The reasons for not seeking care amongst sick persons in our study were totally different from those in a study from the Dominican Republic, where the most frequent reasons were distrust of the clinic staff, shortage of medicines, and dispersion of the rural population [17].

The results of our exploratory study indicate the important role of self-treatment for RI, particularly in rural areas where the accessibility, availability and affordability of healthcare facilities are limited. The reasons for self-treatment were convenience (proximity), cheapness (affordability), and because the illness was mild (severity). The option of self-treatment as the first choice is usually influenced by the perception of severity. The FGD participants in both peri-urban and rural areas reported that they chose self-medication and selftreatment as first line approach in cases of mild RI. In previous studies it was also found that self-treatment was common when the severity of the illness was perceived to be low [18-20]. In Laos, approximately one third to a half of people self-medicate when they become sick [4,21] - findings that are consistent with those of our study. In Guatemala, about two thirds of children with diarrhea and RIs were self-treated by their guardians or relatives and only one third of illnesses were treated by healthcare providers such as pharmacists, doctors, and staff at health posts and centres [22].

A study in the Dominican Republic demonstrated that the choice of health service utilization among caregivers 
of children with RI was determined by location (proximity) and cost [15]. Healthcare-seeking behavior in the current survey was very different between peri-urban and rural areas. If there was no improvement following selftreatment, people in peri-urban area preferred to choose private clinics and pharmacies as their next treatment option, while those in rural areas frequently consulted the village health volunteer and visited the health centre. This may be explained by the difference in the availability and proximity of the healthcare facilities between the two areas. In peri-urban areas, private clinics and pharmacies are readily available and nearby when compared with rural areas. In contrast, hardly any private clinics and pharmacies are available in rural areas, apart from the health centre and village health volunteer. It is obvious that Lao villagers prefer to use the closest healthcare facilities because of the convenience and the low travel cost. The national health survey in 2000 also showed that more people in peri-urban and urban areas went to a pharmacy when they were ill compared with those in rural areas [4]. A study in western Nepal revealed that almost half of episodes of childhood illness were treated by pharmacists and in $15 \%$ of episodes medicines were purchased from pharmacies without consultation [23].

Severity of illness is an important determinant of treatment-seeking behavior $[24,25]$. In our study, the decision to move from one healthcare provider to another, or from self-treatment to seeking some form of treatment, was also influenced by severity of illness or treatment failure. Sick persons did not go back to the same healthcare provider or facility which they had originally visited but to other places. In peri-urban areas, people would seek further care in central hospitals, where a better quality of service and modern technology are available. In rural areas, people would like to seek further treatment in the district or provincial hospital, but are constrained from doing so by distance and cost.

The limitations of this study are that the definition of RI used here included only fever with cough and/or sore-throat - symptoms which do not cover many other respiratory illnesses. Another drawback is that the study relied only on self-reporting illness in the previous 30 days, which may be subject to recall and reporting bias. The study was conducted only in a cross-sectional manner in time, and therefore the proportion of RI found in this survey may not be representative of all times of year, especially the winter.

\section{Conclusions}

The burden of RI and related healthcare-seeking behavior are different between rural and peri-urban areas in Laos, and this is probably due to the differences in environmental and hygienic conditions, availability of healthcare services, and socio-economic status between the two areas. Therefore strategies for healthcare service improvement may also need to differ between the two areas. In peri-rural areas, improvement must be focused on private clinics and pharmacies, while it should be focused on health centres and village health volunteers in remote rural areas. Further studies are required, particularly in urban areas and among specific ethnic groups, in order to determine whether there is a difference in the pattern of healthcare-seeking behavior so that specific strategies for the improvement of healthcare services can be established and implemented practically and appropriately.

\section{Competing interests}

The authors declared that they have no competing interests.

\section{Authors' contributions}

MM, VH, VS developed protocol, collected and analyzed data, and drafted the manuscript. BS, LO, VT, VS, CT, SN, and JP collected data and revised the manuscript. KC and PC analyzed data and revised the manuscript. All authors have read and agreed on the final version of this manuscript.

\section{Acknowledgements}

This study was funded by the U.S. Centres for Disease Control and Prevention. We are very grateful for the involvement and cooperation of all villagers in this survey and for the technical help from Andrew Corwin, Ellen Wan, Brittany Moore, William Moss, and Melanie Kempster. Our grateful thanks go to Ms. Maniphone Sayasane and Dr. Khounkham Xaymounvong for their logistic support. We are very grateful for the support of the former President of the University of Health Sciences, Assoc. Prof. Dr. Som Ock Kingsada and the former Vice-President of the University of Health Sciences, Assoc. Prof. Dr. Sing Menorath. We thank Dr. David Dance for his critical comments and review of the paper. We really appreciate the support from CARE International in Lao PDR. This report was supported by Cooperative Agreement Number 5U10EP424885-05 REVISED from Centres for Disease Control and Prevention (CDC). The contents of the paper are solely the responsibility of the authors and do not necessarily represent the official views of CDC.

\section{Author details}

${ }^{1}$ Faculty of Postgraduate Studies, University of Health Sciences, Vientiane, Lao PDR. ${ }^{2}$ Lao-Oxford-Mahosot Hospital-Wellcome Trust Research Unit (LOMWRU), Microbiology Laboratory, Mahosot Hospital, Vientiane, Lao PDR. ${ }^{3}$ Centre for Clinical Vaccinology and Tropical Medicine, Nuffield Department of Clinical Medicine, Churchill Hospital, University of Oxford, Oxford, UK.

Received: 8 November 2012 Accepted: 30 April 2013

Published: 4 May 2013

\section{References}

1. Bryce J, Boschi-Pinto C, Shibuya K, Black RE, WHO Child Health Epidemiology Reference Group: WHO estimates of the causes of death in children. Lancet 2005, 365:1147-1152.

2. World Health Organization: WHO case definitions for human infections with influenza A (H5N1) virus. 2006. http://www.who.int/influenza/resources/ documents/case_definition2006_08_29/en/.

3. Wardlaw T, Johansson EW, Hodge M: Pneumonia: The forgotten killer of children. UNICEF/WHO; 2006. http://www.unicef.org/publications/files/ Pneumonia_The_Forgotten_Killer_of_Children.pdf.

4. National Statistics Centre: Report on National Health Survey: Health Status of the People in Laos 2000. Ministry of Health 2001. Unpublished report of Ministry of Health.

5. Chimbanrai B, Fungladda W, Kaewkungwal J, Silachamroon U: Treatmentseeking behaviors and improvement in adherence to treatment regimen of tuberculosis patients using intensive triad-model program, Thailand. Southeast Asian J Trop Med Public Health 2008, 39:526-541.

6. National Statistics Centre: Lao People's Democratic Republic. Results from the Population and Housing Census 2005. National Statistics Centre 2005. Unpublished report of National Statistics Centre. 
7. Clague B, Chamany S, Burapat C, Wannachaiwong Y, Simmerman MJ, Dowell SF, Olsen SJ: A household survey to assess the burden of influenza in rural Thailand. Southeast Asian J Trop Med Public Health 2006, 37:488-493.

8. Bloom DE, Canning D, Jamison DT: Health, wealth and welfare. Finance and development 2004. http://heart-intl.net/HEART/110105/Health, Wealth,and.pdf.

9. Sen B: Drivers of escape and descent: changing households fortune in rural Bangladesh. World development 2003, 31:513-534.

10. Wagstaff A: Poverty and Health Sector Inequalities. Bull World Health Organ 2002, 80:97-105.

11. Lahelma $\mathrm{E}$, Arber $\mathrm{S}$ : Health inequalities among men and women in contrasting welfare states. Britain and three Nordic countries compared. Eur J Public Health 1994, 4:213-226.

12. Zaman K, Zeitlyn S, Chakraborty J, de Francisco A, Yunus M: Acute lower respiratory infections in rural Bangladeshi children: Patterns of treatment and identification of barriers. Southeast Asian J Trop Med Public Health 1997, 28:99-106.

13. de Silva MW A, Wijekoon A, Hornik R, Martines J: Care seeking in Sri Lanka: one possible explanation for low childhood mortality. Soc Sci Med 2001, 53:1363-1372.

14. Mbonye AK: Prevalence of childhood illnesses and care-seeking practices in rural Udanda. Scientific World Journal 2003, 3:721-730.

15. Thind A, Andersen R: RI in the Dominican Republic: what are the predictors for health services utilization of young children? Soc Sci Med 2003, 56:1173-1182.

16. Adegboyega AA, Onayade AA, Salawu O: Care-seeking behavior of caregivers for common childhood illnesses in Lagos Island, Local Government Area, Nigeria. Niger J Med 2005, 14:65-71.

17. Ugalde A: Where there is a doctor: Strategies to increase productivity at lower costs. The economics of rural health care in the Dominican Republic. Soc Sci Med 1984, 19:441-450.

18. Stoller EP, Forster LE: Patterns of illness behavior among rural elderly; preliminary results of a health diary study. J Rural Health 1993, 8:13-26.

19. Stevenson FA, Briteen N, Barry CA, Bradley CP, Barber N: Self-treatment and its discussion on medical consultations: how is medical pluralism managed in practice? Soc Sci Med 2003, 57:513-527.

20. Tuan T, Dung VTM, Neu I, Dibley MJ: Comparative quality of private and public health services in rural Vietnam. Health Policy Plan 2005, 20:319-27.

21. National Institute of Public Health: Household survey in the two provinces of Xiengkhouang and Oudomxay. Minist Health 1999. Unpublished report of Ministry of Health.

22. Heuveline P, Goldman N: A description of child illness and treatment behavior in Guatemala. Soc Sci Med 2000, 50:345-364.

23. Sreeamareddy CT, Shankar RP, Sreekumaran BV, Subba SH, Joshi H, Ramachandran U: Seeking behavior for childhood illness - a questionnaire survey in western Nepal. BMC Int Health Hum Rights 2006, 6:7.

24. Rosenstock IV, Becker M: Social learning theory and the health belief model. Health Education Quaterly 1998, 15:175.

25. Yoder PS, Hornik RC: Symptoms and perceived severity of illness as predictive of treatment for diarrhea in six Asian and African sites. Soc Sci Med 1996, 43:429-439.

\section{doi:10.1186/1471-2458-13-444}

Cite this article as: Mayxay et al:: Respiratory illness healthcare-seeking behavior assessment in the Lao People's Democratic Republic (Laos). BMC Public Health 2013 13:444.

\section{Submit your next manuscript to BioMed Central and take full advantage of:}

- Convenient online submission

- Thorough peer review

- No space constraints or color figure charges

- Immediate publication on acceptance

- Inclusion in PubMed, CAS, Scopus and Google Scholar

- Research which is freely available for redistribution 